\title{
EDUCAÇÃO E LUTA PELA TERRA NO BRASIL: A FORMAÇÃO POLÍTICA NO MOVIMENTO DOS TRABALHADORES RURAIS SEM TERRA*
}

\author{
Fabiana de Cássia Rodrigues ${ }^{1}$
}

\begin{abstract}
RESUMO: Nos movimentos que se colocam contra a ordem estabelecida, faz-se necessária uma formaçáo que dê conta de compreender as circunstâncias vividas a partir de suas contradiçóes sociais, numa visão que privilegie a transformação da realidade por aqueles que se colocam em luta. No caso do Movimento dos Trabalhadores Rurais Sem Terra (MST), ao mesmo tempo em que o conflito imediato se dá pela terra, as lutas expressam a permanência da questão agrária como fundamento da elevada exploraçáo do trabalho no Brasil. A questão que se coloca é se os que estão na frente de combate possuem uma visão capaz de articular o olhar sobre as ocupaçóes das quais participam, com a totalidade das relaçóes que determinam a questão agrária em nosso país. Discute-se que a compreensão da totalidade das relaçóes que estão na base da exploração do trabalho náo advém espontaneamente da luta, mas de um trabalho sistemático de formação política articulada com o desenvolvimento da teoria e da prática relativas ao avançar dos embates entre as classes. Sendo assim, neste texto apresentamos nosso entendimento sobre formaçáo política; em seguida, traçamos uma discussão sobre a formação política na pedagogia do MST e, por fim, realizamos uma reflexão crítica a esse respeito.
\end{abstract}

Palavras-chave: Formação política. Educação. MST. Questão agrária.

\section{EDUCATION AND STRUGGLE FOR LAND IN BRAZIL: POLITICAL FORMATION IN THE LANDLESS WORKERS' MOVEMENT}

ABSTRACT: In the movements that arise against the established order, it is necessary a political formation that is able to understand the circumstances experienced from its social contradictions, in a vision that favors the transformation of reality by those who put themselves in struggle. In the case of the Landless Workers' Movement (MST), while

\footnotetext{
*Este artigo apresenta resultados do Projeto de Pesquisa de Doutorado: MST: Formação Política e Reforma Agrária nos anos de 1980, desenvolvido no Programa de Pós-Graduaçáo da Faculdade de Educaçáo da Unicamp, financiado pela Coordenaçáo de Aperfeiçoamento de Pessoal de Nível Superior (CAPES).

${ }^{1}$ Universidade Estadual de Campinas, Faculdade de Educação - Campinas (SP), Brasil.

E-mail: fabicrod@unicamp.br

DOI: 10.1590/ES0101-73302017165251
} 
the immediate conflict is over land, struggles express the permanence of the agrarian question as the foundation of elevated labor exploitation in Brazil. The question that arises is whether those in struggle articulate the goals and meaning of the occupations in which they participate with the multiple determinations of the agrarian question in our country. It is argued that an understanding of the totality of the relationships that are in the base of labor exploitation does not come from struggle spontaneously, but rather from a systematic work of political education articulated with the development of theory and practice relative to the advance of the conflicts between classes. Thus, in this paper we present our understanding of political formation; then we draw a discussion of the political formation in MST's pedagogy; and finally present a critical reflection on this.

KEYWORDS: Political formation. Education. MST. Agrarian question.

\section{L'ÉDUCATION ET LA LUTTE POUR TERRE AU BRÉSIL: LA FORMATION POLITIQUE DANS LE MOUVEMENT DES Travailleurs RuRauX SANS TerRe}

RÉSUMÉ: Dans des mouvements sociaux qui se positionnent contre l'ordre établi il faut construire une formation politique qui ait la capacité d'appréhender les circonstances vécues à partir de leurs contradictions sociales, en privilégiant la transformation de la réalité par ceux qui sont engagés dans cette lutte. Dans le cas du Mouvement des Travailleurs Ruraux Sans Terre (MST), les luttes expriment, à la fois, le conflit immédiat pour l'accès à la terre et la continuité de la question foncière en tant que fondement du taux très élevé d'exploitation du travail au Brésil. La question à laquelle nous nous confrontons est de savoir si ceux qui étaient sur le front des actions réalisées par le MST articulaient les objectifs et le sens des occupations des terrains agricoles auxquelles ils participaient avec les déterminations multiples de la question agraire au Brésil. Dans ce sens, on montrera que la compréhension de la totalité des relations qui sont à la base de l'exploitation du travail n'advient pas spontanément de la lutte, mais d'un effort systématique de formation politique articulé avec le développement de la théorie et de la pratique relatives au progrès des conflits entre les classes. Ainsi, d'abord, nous présenterons notre interprétation de l'importance et du sens de la formation politique. Ensuite, nous nous focaliserons sur la place de la formation politique au sein de la pédagogie du MST et, enfin, on en proposera une évaluation critique.

Mots-clés : Formation politique. Éducation. MST. Question agraire. 


\title{
Introdução
}

\begin{abstract}
Não há como combatê-los e destruí-los sem um esclarecimento prévio dos espíritos, dos que são potencialmente inconformistas e dos que apenas contam como os "condenados do sistema", mas não sabem como identificar e extinguir a espoliação que sofrem de maneira cruel e permanente. Todos, inclusive os conservadores, "esclarecidos" ou "obnubilados", precisam tomar consciência do que é o poder conservador no Brasil, quanto ele nos custa, em sacrifícios humanos, em iniquidades sociais, econômicas e culturais, em incapacidade de integraçáo e de autonomia nacionais, devastação de recursos materiais e humanos, em perversão do patriotismo e em solapemento do nacionalismo, em farisaísmo crônico e em constante participação atrasada do "progresso", em comercialização das relaçóes de dependência em face do exterior, pela qual se negocia, em troca de nada ou de quase nada, as futuras gerações e o porvir da Nação (FERNANDES, 1975, p. XVI).
\end{abstract}

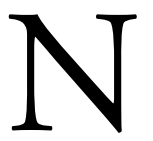

um país como o Brasil, cuja particularidade é marcada pelo nosso passado colonial - base sobre a qual se ergueu um capitalismo dependente e subdesenvolvido —, se faz necessário indagar: como romper com seus impasses históricos? A saída seria a reforma do capitalismo ou a revolução? Essas questóes cobram respostas da teoria, que deve ser formulada a partir do desvendamento de nossa trajetória histórica e é premente para os movimentos sociais que contestam a ordem vigente (FERNANDES, 2006).

A ascensão das massas na década de 1980 no Brasil relacionou-se com reivindicaçóes reformistas, no contexto de luta contra a ditadura. Cabe-nos antes de tudo compreender o real significado da luta por reformas no capitalismo dependente, cujo núcleo do poder se encontrava, sob a ditadura, nas mãos de uma classe historicamente conservadora, rígida, monolítica e inabalavelmente carrancista, como afirma Florestan Fernandes (1975). Uma das exigências teóricas para os que se colocaram em luta pela reforma agrária no Movimento dos Trabalhadores Rurais Sem Terra (MST), durante a década de 1980, foi a compreensão dessa luta, de seus limites e suas possibilidades em nossa particularidade histórica. Ao longo desse período, um movimento que nasceu como fruto de ocupaçóes na regiáo Sul se nacionalizou e se colocou no debate nacional sobre a reforma agrária. Entre as tarefas que se colocaram estava a formação política da militância.

Neste artigo tratamos da formação política no $\mathrm{MST}^{1}$. Ela é vista como um dos âmbitos da educação, a qual é entendida como o processo pelo qual o homem se torna homem durante a sua vida, como afirma Manacorda (2007):

O homem não nasce homem [...]. Grande parte do que transforma o homem em homem forma-se durante a sua vida, 
ou melhor, durante o seu longo treinamento por tornar-se ele mesmo, em que se acumulam sensaçóes, experiências, noçôes, formam-se habilidades, constroem-se estruturas biológicas - nervosas e musculares — não dadas a priori pela natureza, mas fruto do exercício que se desenvolve nas relaçóes sociais, graças às quais o homem chega a executar atos, tanto "humanos" quanto "não naturais", como o falar e o trabalhar segundo um plano e um objetivo. Ou talvez o homem nasça homem, mas apenas enquanto possibilidade, que, para se atualizar, requer, sem dúvida, uma aprendizagem num contexto social adequado, o que é expresso com sintética clareza pelas palavras de Luporini: o homem nasce, de fato, na sociedade, mas não nasce social; assim se torna pela educação que o faz assumir, pouco a pouco, aquela sua situação de fato e originária (MANACORDA, 2007, p. 22).

Assim, a educação não é dada pela natureza, ela é produzida histórica e coletivamente, direta e intencionalmente em cada indivíduo singular. Logo, o objeto da educação "[...] diz respeito, de um lado, à identificação dos elementos culturais que precisam ser assimilados pelos indivíduos da espécie humana para que eles se tornem humanos e, de outro lado e concomitantemente, à descoberta das formas mais adequadas para atingir esse objetivo" (SAVIANI, 2008a, p. 13). Tal como afirma Mészáros (2005), baseado em Paracelso, entendemos que a educação abrange toda a vida do indivíduo, desde o momento do seu nascimento até a sua morte.

No entanto, o processo de formação humana não é neutro. A educação encontra-se determinada pela sociedade de classes e seus interesses antagônicos. "O seu entrelaçamento com as lutas de classes não é apenas uma 'triste imperfeição’ da história, pois a luta de classes é um instrumento, até o presente, necessário para o desenvolvimento social" (LEHER, 2010, p. 22). Sob o capital, quanto mais "avança" a sociedade capitalista, mais unilateralmente centrada na produção de riqueza como um fim em si mesma ela se torna. Em paralelo, a educação volta-se crescentemente tanto para a internalização de que vivemos sob uma ordem imutável e "natural" quanto para embeber-nos nos valores da sociedade da mercadoria, como algo lógico —, a fim de perpetuá-la (MÉSZÁROS, 2007).

O desafio que se coloca às classes exploradas é se opor a essa naturalização da realidade e de sua imutabilidade. Para Mészáros (2007), a educação deve voltar-se para o desenvolvimento contínuo da consciência socialista fundada na busca pela transformação estrutural da sociedade. A tarefa não poderia ser maior: trata-se de formar indivíduos para a compreensão real dos problemas da sociedade, a partir das "[...] causas historicamente originadas e determinações estruturais claramente identificáveis, bem como desafiáveis” (MÉSZÁROS, 2007, p. 298). Nesse sentido, o real significado de educação é "fazer os indivíduos viverem posi- 
tivamente à altura dos desafios das condiçóes sociais historicamente em transformação" (MÉSZÁROS, 2007, p. 205).

O desafio de superar a nossa questão agrária se impôs com força nos anos de 1980. No MST, a busca imediata e que motivava a luta era a questáo da terra; por outro lado, o aparecimento desse movimento expressava a permanência da questão agrária. Esta constitui fundamento da extrema exploração da força de trabalho no país, bem como condiciona a correlação de forças entre trabalho e capital, que pende significativamente em favor deste. Por esse raciocínio, é possível afirmar que a elevada concentração da terra está na base estrutural do capitalismo que aqui se desenvolve. Por isso, a luta por terra no Brasil não se restringe a uma questâo fundiária: é uma luta, em nossa visão, que diz respeito aos interesses do conjunto da classe trabalhadora. Desse ponto depreendem-se as razóes da radicalidade dessa luta, segundo o significado específico que ela possui nessas condições históricas, bem como a compreensão das forças políticas de direita que se organizam para impedir qualquer alteração nesse sentido (RODRIGUES, 2013).

A luta pela terra no Brasil articula inexoravelmente os temas "reforma" e "revolução", pois, de um lado, trata-se de uma reivindicação "clássica" no contexto da Revolução Burguesa - como se desenrolou na história da constituição do capitalismo em diversos países -, e de outro, na realidade brasileira, a conquista de uma reestruturação da propriedade da terra ampla e radical certamente ameaçaria as bases da dependência e do subdesenvolvimento que conformam o capitalismo no Brasil, contendo, assim, uma forte potencialidade revolucionária.

No entanto, questiona-se: aqueles que se colocam na luta imediata por terra possuem essa visão sobre a totalidade das relações que determinam a questão agrária no Brasil? Seria possível e necessário que a massa do movimento enxergasse as razóes mais amplas que motivam seus oponentes e barram a realizaçáo de uma reforma agrária no país, bem como os nexos que essa luta enseja entre reforma e revolução?

Partindo das ideias desenvolvidas por Lênin, acreditamos que essa visão mais ampla não poderia surgir espontaneamente na luta, nas ocupaçôes, por exemplo. Ela seria oriunda de um trabalho de formação política levada a cabo por um elemento externo à luta imediata. O professor Plínio de Arruda Sampaio Júnior sintetiza na passagem a seguir a defesa que Lênin fazia sobre esse ponto:

O raciocínio é o seguinte: a incapacidade do movimento operário de impor à luta de classes, por conta própria, um radicalismo que transcenda os marcos do regime capitalista é atribuída à natureza fetichista das relaçóes de produção capitalistas e ao caráter alienante do processo de trabalho. No contexto de uma situaçáo concreta que camufla os elementos essenciais da realidade, a visão crítica depende de um elemento externo às relaçóes imediatas do proletariado com o capital. Somente quando exposto à reflexão 
crítica da realidade, que desnuda as forças motrizes que determinam a luta de classes, o proletariado tem condiçóes de realizar um salto de qualidade no seu grau de consciência de classe e adquirir a clareza política e a consistência ideológica necessárias para impulsionar a luta revolucionária (SAMPAIO JUNIOR, 2011, p. 23).

Portanto, entre os desafios que se impunham ao movimento estava o de clarificar as possibilidades da luta, bem como a justeza das reivindicaçóes e, principalmente, o de identificar seu horizonte, relativo ao significado maior que a questão agrária tem historicamente no país. Essas tarefas relacionam-se ao desenvolvimento da consciência política e se colocavam no âmbito da formação política daqueles que compunham o movimento.

A formação política deveria voltar-se à instrução a respeito do sentido da luta, desde as razóes econômicas e políticas que determinam os embates cotidianos até a elucidação das distintas formas e casos de exploração, para iluminar "o significado e a essência da exploração em seu conjunto, [...]" e "[...] compreender o regime social que se assenta na exploração do trabalho pelo capital” (LÊEIN, 1981, p. 107). Por essa análise, a formação estaria ligada ao esclarecimento do verdadeiro objetivo da luta dos trabalhadores, que consistiria na superação do modo de produção capitalista na particularidade histórica do Brasil. Desse modo, a história, feita pelos homens, passaria, cada vez mais, a ser forjada de maneira consciente: "A medida que os homens fazem a história, ampliando e aprofundando sua obra, deve crescer também a massa da população que a forja de maneira consciente" (LÊNIN, 1981, p. 563).

Para Lênin, haveria uma tríade indissociável entre a luta econômica luta coletiva dos operários contra os patróes para conseguirem condições vantajosas de venda da força de trabalho — a luta política — exigências realizadas em todas as manifestaçóes da vida política e social - e a luta teórica. Contra o "economicismo", expresso no movimento operário como o apego unicamente às lutas sindicais e ao culto da espontaneidade, o autor reivindica a urgência da luta teórica, em suas palavras:

[...] os dirigentes deverão instruir-se cada vez mais em todas as questôes teóricas, libertar-se cada vez mais da influência da fraseologia tradicional, própria da antiga concepção do mundo, e ter sempre presente que o socialismo, desde que se tornou uma ciência, exige ser tratado como uma ciência, isto é, ser estudado. A consciência assim alcançada e cada vez mais lúcida deve ser difundida entre as massas operárias com zelo cada vez maior, deve consolidar-se cada vez mais fortemente a organização do partido e a dos sindicatos (LENIN, 1986, p. 99). 
A luta teórica corresponderia ao estudo profundo e sistemático da realidade e de suas determinaçóes, ao desvendamento das causas da exploração do trabalho e toda a dinâmica do modo de produção capitalista. Ou seja, em paralelo à luta econômica e à luta política se colocaria o desenvolvimento teórico vinculado à visão do socialismo como ciência.

No âmbito da luta teórica e no da formação política teria papel fundamental uma organização revolucionária que estabelecesse as relaçóes entre a teoria e as práticas de luta voltadas à transformação radical da realidade. No caso do MST, é possível identificar uma relação muito próxima, desde as origens, com o Partido dos Trabalhadores (PT), que surge no mesmo período. Desse modo, seria o PT essa organização voltada a dar um sentido maior para luta? Segundo declaraçóes de lideranças do movimento - conforme discutiremos nos tópicos a seguir —, eram depositadas no PT as esperanças de transformação mais ampla da sociedade, que permitiriam a realização das reivindicaçóes do movimento.

\section{A pedagogia do Movimento do Trabalhadores Rurais Sem Terra}

Assim como a luta pela terra na particularidade do capitalismo brasileiro adquire caráter subversivo, a luta pela educação no campo tem sido historicamente rechaçada pelos "de cima”. Isso pode ser evidenciado pelas perseguiçóes sofridas pelas escolas do MST, que padecem de falta de recursos públicos e constantes ameaças de fechamento ${ }^{2}$.

O MST se coloca na contra-hegemonia ao defender uma proposta educacional que envolve: a ampliação do número de escolas para atendimento dos acampamentos e assentamentos, a introdução do tema das lutas dos trabalhadores e sua importância nos conteúdos a serem desenvolvidos, bem como uma formação política para sua militância, que a prepare para a luta pela terra.

Simultaneamente, em especial a partir da década de 1990, as políticas públicas educacionais vêm sendo impregnadas pelo ideário neoliberal, por projetos formulados, por exemplo, pelo Banco Mundial, e que atendem aos interesses das naçôes centrais e agridem crescentemente a classe trabalhadora brasileira. Segundo Frigotto (2000), vivemos nesse período a década perdida para a educação no país, já que todas as políticas do governo Fernando Henrique Cardoso responderam à lógica dos ajustes econômicos impingidos pelos organismos internacionais:

Pela primeira vez em nossa história, a pedagogia do Banco Mundial e da CNI [Confederaçáo Nacional da Indústria] é a pedagogia oficial do Ministério da Educação. Trata-se de uma educaçáo voltada para desenvolver competências específicas, tendo em vista criar pessoas empregáveis, segundo as necessidades do mercado. Não há mais responsabilidade coletiva, pois tudo se resume ao universo do indivíduo e da relação que ele consiga estabelecer 
com o mercado. Cada um deve construir seu destino, e procurar ser bem sucedido por conta própria (FRIGOTTO, 2000, p. 122).

Ou seja, a educaçáo se dirige a perpetuar as desigualdades e aprofundá-las, pois sob o modo de produção capitalista e sua Lei Geral de Acumulação, o número de "bem sucedidos" é cada vez menor. Logo, o destino dos trabalhadores é a crescente espoliação. A partir da ideologia neoliberal, expressa nas políticas do Ministério da Educação, a responsabilidade pelo fracasso cabe inteiramente ao indivíduo, que não foi capaz de desenvolver sua "empregabilidade". Segundo Saviani (2008b):

Configura-se, entâo, nesse contexto, uma verdadeira "pedagogia da exclusão". Trata-se de preparar os indivíduos para, mediante sucessivos cursos dos mais diferentes tipos, se tornarem cada vez mais empregáveis, visando a escapar da condição de excluídos. E, caso não o consigam, a pedagogia da exclusão lhes terá ensinado a introjetar a responsabilidade por essa condição (SAVIANI, 2008b, p. 429).

Na contramão, se colocam as ideias e práticas pedagógicas desenvolvidas pelo MST ao longo de sua história. Roseli Caldart, educadora do movimento, sistematizou essas ideias e práticas produzidas coletivamente em sua tese de doutorado, cujo título é "Pedagogia do Movimento Sem Terra". Segundo essa tese, a escola, apesar de ser fundamental, é apenas um dos âmbitos no qual ocorre a educação. Trata-se de uma concepção mais abrangente de educação, vista como formação humana. Pensada dessa maneira, são estabelecidos nexos entre educação e vida produtiva. Caldart (2004) demonstra as influências de Marx para a compreensão de educação a partir de seus determinantes estruturais, ou seja, pelo modo no qual a sociedade organiza a produção e reprodução material da vida. Daí a importância de enxergar o trabalho como princípio educativo:

[...] se produzindo a sua existência, as pessoas se educam, então compreender a dimensão educativa da vida produtiva é fundamental para compreender mais profundamente o processo de formação humana, bem como para conseguir desdobrá-lo em açóes educativas intencionais e planejadas, tais como as que acontecem na escola. Foi a partir dessa compreensão que se chegou à formulação pedagógica do trabalho como princípio educativo [...] (CALDART, 2004, p. 85).

Essa reflexão, que reforça o lugar das relaçóes sociais nos processos de formação humana, é desdobrada para a análise de que o movimento seria um princípio educativo, ou seja, o MST seria visto "[...] como um sujeito pedagógico [...], como uma coletividade em movimento, que é educativa e que atua intencionalmente no processo de formação das pessoas que a constituem" (CALDART, 2004, 
p. 315). Visto dessa maneira, é possível analisar a formação humana dos sem-terra no processo de constituição e consolidação do MST.

Sintetizaremos os três momentos que Caldart identifica na história do MST, relacionando com formas fundamentais da luta na formação do sem-terra, como a ocupação e o acampamento.

$\mathrm{O}$ primeiro desses momentos históricos corresponde à gênese e ao nascimento do MST e situa-se cronologicamente entre os últimos anos de 1970 e 1986/87. Ao final desse período, o MST já estava organizado em 12 estados e havia acumulado conquistas e aprendizados significativos. Caldart (2004) o sintetiza da seguinte forma:

Como síntese das marcas da formação dos sem-terra produzidas nesse primeiro momento podemos destacar então: a construçáo da decisão de rebelar-se contra sua condição de sem (a) terra, o jeito de fazer essa luta e o orgulho de passar a atender também por um outro nome que não apenas o seu pessoal: quem é você: sou Sem Terra, sim senhor, (...) e através da luta e das formas que ela vai assumindo, a passagem do sem-rosto a cidadáo, ou seja, a construção da identidade sem-terra como sujeito social de direitos: pessoas, coletivos que se sabem com direitos e que se organizam para conquistá-los (CALDART, 2004, p. 129).

$\mathrm{Na}$ construção da decisão de rebelar-se e colocar-se em luta pela terra, a formação política adquiriu papel fundamental, ou seja, o saber-se detentor de direitos tem a ver com:

- a conscientização a respeito de como a terra é distribuída e apropriada no Brasil;

- o acesso à legislação e aos dados que informam sobre a concentração fundiária nas diversas regióes do país; e

- o conhecimento dos interesses do grande capital envolvidos na exploração do trabalho no campo.

Assim, entre estar na posição de classe explorada e se colocar conscientemente na luta por terra, existe o momento da formação política. Nesse momento, como afirma Caldart (2004), além da Bíblia, teve papel fundamental o Estatuto da Terra, materiais de conhecimento indispensável para o trabalho de base junto aos sem-terra.

A tática de luta escolhida, logo no início, foi a ocupação, a qual adquiriu centralidade na própria demarcação do surgimento do MST — que coincide com 
a primeira ocupação de terra. Em torno da ocupação foram construídos princípios organizativos e uma metodologia própria de educação do povo:

Do ponto de vista pedagógico, a ocupação de terras é, das vivências aqui analisadas, talvez a mais rica em significados socioculturais que formam o sujeito Sem Terra e projetam mudanças lentas no modo das pessoas se posicionarem diante da realidade, do mundo. Ao provocar uma ruptura fundamental com determinados padróes culturais hegemônicos, prepara o terreno para os aprendizados desdobrados das demais vivências (CALDART, 2004, p. 167).

Para aqueles que entram na luta faz-se necessário, logo de início, diferenciar o "ocupar" e o "invadir". José Gomes da Silva (1997) traz uma explicação jurídica bastante elucidativa, que serviu como referência importante desde o início do movimento para o trabalho com a base. Utilizando-se das ideias de professores de Direito - como Fabio Comparato, Luiz Edson Fachin e Régis de Oliveira Silva (1997, p. 112) chama a atenção para a peculiaridade da propriedade da terra: “[...] num país de famintos como o nosso, é radicalmente diferente do direito de propriedade sobre qualquer outra coisa. [...] É mais de vida — e de vida alheia à do proprietário - do que de patrimônio, que se deve falar, quando se trata dele". Logo, enquanto "invadir" significa tomar alguma coisa de alguém, "ocupar” diz respeito a preencher um vazio, especificamente, terras que não cumprem sua função social. Por isso, desde o início, o trabalho de formação política envolveu conscientizar aqueles que se punham em luta a respeito de qual problemática envolvia a questão da apropriação das terras no Brasil.

Caldart (2004) aponta três dimensóes na formaçáo dos sem-terra, nesse momento decisivo relativo à ocupação de terras: a primeira seria a formação para a contestação social ou para a rebeldia organizada, passando a se rebelar contra o destino de morte que, anteriormente, parecia inevitável. Aos poucos eles vão percebendo que o enfrentamento coletivamente organizado é a única saída possível para a conquista do objetivo almejado. Romper com a ideologia plenamente arraigada da propriedade privada é um dos grandes desafios e resulta dessa formação para a contestação: “[...] Para ocupar uma terra é preciso que eles próprios, os semterra, rompam com o valor supremo da propriedade privada, pelo menos ao ponto de considerar que, em uma ordem de prioridades, ela deve estar subordinada a valores como a vida e o trabalho" (CALDART, 2004, p. 171).

A segunda dimensão seria a formação para a consciência de classe, uma vez que a luta clarifica as diferenças entre a burguesia organizada, de um lado, e os explorados organizados no movimento, de outro. A terceira dimensão seria a do reencontro com a vida, uma vez que retomam a possibilidade de produzir por meio da terra e, assim, garantir seu sustento. 
Outra forma de luta utilizada desde o início do movimento foi o acampamento, quase uma cidade de barracos de lona preta, com uma população de centenas ou milhares de famílias que se organizam para dar continuidade às açóes da luta. Isso pode ocorrer na própria terra ocupada, na beira da estrada ou em áreas para onde são deslocadas as famílias após despejos. Segundo Caldart (2004):

O acampamento é uma forma de luta largamente utilizada pelo MST com o triplo objetivo de educar e de manter mobilizada a base sem-terra, de sensibilizar a opinião pública para a causa da luta pela terra, e de fazer pressão sobre as autoridades responsáveis pela realização da Reforma Agrária (CALDART, 2004, p. 177).

O acampamento seria um grande espaço de socializaçáo dos sem-terra, que passam a viver coletivamente, sendo esse, segundo Caldart (2004), um dos aprendizados fundamentais que ele proporciona. A situação de privação, a falta de condiçôes materiais mínimas para a sobrevivência leva à elaboração de laços de solidariedade:

Solidarizar-se com o outro não é, nessa circunstância, uma intenção, mas uma necessidade prática, o alimento não é suficiente para todos, a repressão pode vir contra todos, o vento pode destruir o barraco de muitos, a dúvida e a vontade de desistir de tudo pode chegar a uns quantos, ou a cada pessoa em algum momento; e o principal argumento da necessidade talvez seja o que a vitória virá para todos, ou não virá para ninguém. Ou seja, a condição gera a necessidade de aprender a ser solidário e a olhar para a realidade desde a ótica do coletivo e não de cada indivíduo ou de cada família isoladamente (CALDART, 2004, p. 179).

Outros aprendizados proporcionados aos acampados seriam:

- perceberem-se cidadáos por meio da conquista do direito à participação nas decisóes que envolvem o encaminhamento das açóes do movimento;

- a construção de novas relações interpessoais, tais como as alteraçóes nas atribuiçôes do homem e da mulher na família e a possibilidade de participação dos mais jovens nas decisōes; e

- novas referências educativas para as crianças advindas da comunidade que se forma.

Ao estarem juntos e conhecerem as histórias de vida uns dos outros, haveria a possibilidade de chegarem à compreensão de que fazem parte da história, uma vez que mudam os lugares e as datas, mas os fatos são muito parecidos - a origem pobre e trabalhadora dos que estão sob a lona preta os fazem enxergar 
a semelhança de suas trajetórias. Com essas características pedagógicas, o acampamento se tornou uma das marcas da luta dos sem-terra.

O segundo momento histórico — a partir de 1987 — seria o da constituição do MST como uma organização social, indo além do caráter temporário de um movimento de massas. A luta pela terra continuou sendo o cerne do movimento, porém, novas reivindicaçóes e lutas foram inseridas em sua pauta. O MST deixou de ser o movimento somente daqueles que reivindicam terra para ser também daqueles que já a haviam conquistado. Uma vez assentados, era necessário se colocarem na luta por crédito, estradas, saúde e educação, e, para tanto, o enfrentamento coletivo a partir do movimento era fundamental. Além disso, passou-se a buscar no assentamento relaçooes sociais alternativas, apontando para novas formas de organização da produção e do campo como um todo. Na década de 1990 surge o Sistema Cooperativista dos Assentamentos e, em 1992, a Confederação das Cooperativas da Reforma Agrária do Brasil (CONCRAB).

A autora localiza o terceiro momento histórico no final da década de 1990, que se prolonga até a data em que ela redige o texto - no início dos anos 2000. Seria nessas circunstâncias, segundo a autora, que o MST se insere na luta por um projeto popular de desenvolvimento para o Brasil. O movimento se inseria em lutas mais amplas, como aquelas relativas à educação para o campo e contra a privatização da Vale. Em 1998, o MST apoiou abertamente a candidatura de Lula para presidência, tentando realizar um trabalho com a sua base para distinguir os projetos políticos em disputa na época — o do Partido da Social Democracia Brasileira (PSDB) e o do PT.

Foi crescendo a percepção do MST em relação à ampliação das lutas, ao fato da luta pela reforma agrária estar relacionada com várias outras e, especialmente, à necessidade de formulá-la a partir de um determinado projeto de país. Esse foi o desafio colocado ao MST e, contraditoriamente, o partido no qual se apostavam as fichas da mudança, da transformação social e da realização da reforma agrária chega ao poder e não as concretiza.

\section{Reflexão crítica sobre a formação política na pedagogia do Movimento dos Trabalhadores Rurais Sem Terra}

Nos três momentos analisados é possível constatar avanços nas práticas e na formulação da pedagogia dos sem-terra, mas pode-se, também, identificar possíveis limitaçóes. Intelectuais de dentro e de fora do movimento vêm realizando reflexóes nesse sentido, buscando pensar os desafios da formação política para o avanço das lutas.

A pesquisadora Maria Cecília Turatti (2005) realizou a análise de acampamentos no estado de São Paulo. Seu trabalho aborda uma forma de luta 
pouco estudada na academia, ao mesmo tempo que realiza críticas importantes que podem ser feitas às experiências do acampamento e à formação política ensejada.

Turatti (2005) ressalta que os acampados recorrem ao movimento pela ausência absoluta de alternativas e, ao invés de apontar os aspectos positivos dos aprendizados proporcionados pela luta, a autora aponta a conflitualidade permanente, gerada pelas circunstâncias miseráveis em que se encontram, uma vez que: "[...] torna-se deveras complexo estabelecer laços cordiais de barriga vazia" (p. 112). A sociabilidade gerada é bastante fragilizada, pois muitos problemas aparecem, entre eles a questão da hierarquia, da distribuição do poder e da submissão às lideranças; a dificuldade em estabelecer laços de solidariedade após algum tempo acampados; e a prática da difamação.

Nesse contexto, o sacrifício de ficar acampado é fruto especificamente da necessidade — revestida de pouco ou nenhum componente ideológico — situação dificultada pela restrição que o movimento parecia ter com a extensão da formação de quadros para um maior número de pessoas. A autora reconhece que a formação política consiste num trabalho árduo e vagaroso. No entanto, “[o] incentivo à ampliação de possibilidades para que os membros da base do MST travassem contato com mais atividades educativas credenciaria o movimento a defender com mais veemência e respeito os ideais de justiça e igualdade que apregoa" (TURATTI, 2005, p. 113). Importante salientar que essas críticas são elaboradas segundo uma visão que apreende a alta relevância do MST, bem como atribui, em grande medida, essas limitações ao modo de produção no qual estamos inseridos e sua lógica perversa de condução à barbárie:

Os filhos da lona preta são frutos de uma formação histórico-social que os enxotou para além da linha de sobrevivência. O MST assume o papel de reconduzi-los ao mundo social, ainda que em uma dimensão conservadora — porque não reconhece a amixia patente nesse projeto de cooperaçáo pacífica com o inimigo tentando conceder-lhes um lugar no processo produtivo e uma "carteirinha" de consumidor. Mas há uma latência revolucionária intrínseca ao MST, pensado menos como instituição, mas sobretudo como fenômeno social, que nos permite ainda acreditar em mudanças grandiosas (TURATTI, 2005, p. 114).

Ademar Bogo (1999; 2008; 2011), liderança e intelectual do movimento, vem refletindo sobre a questão da formação política, tendo publicado livros que abordam essa temática. $\mathrm{Na}$ publicação mais atual, Bogo faz uma apreciação crítica sobre a organização e a formação política no interior dos movimentos sociais, apontando algumas limitaçóes das práticas e das elaboraçôes teóricas que podem afligir o próprio MST. A partir da via aberta por suas análises, procuraremos desenvolver questionamentos em torno de algumas das ideias expostas por Caldart (2004). 
$\mathrm{O}$ autor descreve o momento atual e os desafios para os movimentos sociais como um todo da seguinte maneira:

Nos momentos de descenso da luta de classes, como este que vivemos na primeira década do século 21 , quando as táticas experimentadas começam a perder a importância, as reaçóes espontâneas das massas também diminuem, e as entidades e siglas partidárias, por falta do movimento ativo das forças, se debilitam e perdem a potencialidade das proposiçôes e do comando. É como se, de um momento para outro, "ninguém" mais escutasse os chamados para a luta e se fechasse em si, desconsiderando inclusive a importância da unidade com as demais forças do mesmo campo ideológico (BOGO, 2011, p. 8).

Nessa citação e mais adiante no seu texto, Bogo (2011) chama a atenção para a reavaliação das táticas utilizadas até então na luta da esquerda:

Os instrumentos existentes que comandaram as diretrizes táticas no período anterior são colocados à prova, e os que se atualizam reformulam-se e seguem; os demais tendem a perder a importância, e, embora continuem existindo, já não preocupam a ordem dominante (BOGO, 2011, p. 26).

Décadas depois da primeira ocupação que ensejou a criação do MST, a principal tática de luta do movimento passa a ser repensada. Ao mesmo tempo, as questóes colocadas no presente nos fazem olhar sob novas perspectivas para seus possíveis limites. Em nosso trabalho, não acreditamos que a ocupação, enquanto forma de luta, esteja superada; apenas apontamos a importância de considerá-la a partir de uma estratégia política mais abrangente.

Assim como afirma Bogo (2011, p. 13), acreditamos que a questão estratégica de primeira ordem seria: “(...) qual será a natureza da revolução brasileira e, dentre todas as forças hoje, quais são as que sofrem mais as consequências da exploração capitalista?"

No mesmo sentido da pergunta supracitada, Bogo foi indagado em um debate do V Encontro Brasileiro de Educação e Marxismo (EBEM), ocorrido entre 11 e 14 de abril de $2011^{3}$. Após explicar detalhadamente a crise atual vivenciada pelo MST e afirmar que as ocupaçóes perderam seu potencial de enfrentamento diante da tamanha dominação que o capital exerce sobre o campo brasileiro, lhe foi feita a pergunta: "Existem problemas teóricos quanto à interpretação da revolução brasileira que estariam na base da crise vivida pelo MST?" A resposta foi a seguinte:

(...) o MST não tem, nem nunca teve uma interpretação sobre a revolução brasileira, o movimento não tem condiçóes de produzir teorias científicas, uma vez que não tem nem 
estrutura, nem recursos para isso. O MST nasceu juntamente com o PT e constituía uma tática, enquanto a estratégia estava com o PT (BOGO, 2011).

Extraímos da análise de Bogo que o MST possuía a tática de luta baseada no enfrentamento, em grande medida ensejado pela ocupação, com papel crucial na formação dos sem-terra e de sua consciência política, tal como destacado por Caldart (2004). Ocorre que, paralelamente a essa tática de luta, havia a necessidade de traçar uma estratégia maior de condução do movimento, uma vez que outros desafios, além da imediata conquista da terra, entravam em questão, tais como: a luta por uma reforma agrária ampla, uma política de apoio aos produtores assentados, um financiamento e uma educação voltados a esses beneficiários. Além do que, dado o caráter estratégico e basilar que a produção agrícola possui na economia e na sociedade brasileira, era premente colocar a tática de luta do MST dentro de uma estratégia maior de país, a qual, segundo Bogo, era capitaneada pelo PT. Por não fazer parte do escopo deste trabalho, náo nos alongaremos aqui em desenvolver as consequências desse atrelamento umbilical entre MST e PT. No entanto, ao chegar ao poder federal — a partir de 2002 —, esse partido não avançou na concretização da tão almejada reforma agrária e não alterou essencialmente a política agrária e agrícola dos governos anteriores. Esses fatos, somados à expansão do agronegócio - levada a cabo com forte participação de interesses estrangeiros - colocou o MST numa forte crise que se prolonga até os dias atuais.

A questáo da estratégia mais ampla do movimento estaria fortemente vinculada a uma interpretação histórica do Brasil que captasse suas particularidades, esforço realizado por intelectuais como Caio Prado (2000; 1979), Florestan Fernandes (2008) e Octávio Ianni (1984). Em nossa visão, a formação política do movimento deveria estar primordialmente vinculada a esse tipo de análise, construindo um horizonte maior para as lutas, não baseado em utopias, mas numa interpretação científica da realidade, a partir dos interesses das classes exploradas.

Segundo Marx e Engels, a superação do modo de produção capitalista não se pauta em utopias. A defesa marxiana do socialismo náo se funda em um esforço imaginativo de como a sociedade poderia ser diferente do que é. Ela parte da análise científica da gênese, do desenvolvimento e da superação do capital e constata os germes de uma nova sociedade, com possibilidades reais de ocorrer, tendo em mente as contradiçóes e tendências do modo de produção sob o qual vivemos.

Engels ressaltou esse ponto no texto "Socialismo Utópico e Socialismo Científico" — seguido por Lênin —, ao insistir sobre a necessidade do socialismo ser tratado como ciência. Essa é uma questão teórica da mais alta relevância: a análise científica do presente e de nossa história deve fazer parte do projeto educacional de um movimento que se coloca contra a ordem vigente. Nesse contexto, a educação política dos militantes teria como parte fundamental o desafio da compreensão 
das particularidades históricas de nosso capitalismo, vislumbrando superar suas contradições na luta para além do capital. Também nesse ponto Bogo (2011) parece identificar a problemática:

O problema hoje se localiza em como resolver a questáo entre o conhecimento "empírico" e o conhecimento científico no seio das lutas e dos movimentos sociais. O conhecimento científico é vital para compreender as transformaçôes estruturais na base produtiva, as mudanças na superestrutura de poder do Estado e todos os demais aparelhos repressivos das empresas capitalistas, as profundas mudanças que estão ocorrendo na sociedade civil, seja no padrão de consumo, seja no avanço da individualização ou pela desconsideração por aquilo que é verdadeiramente humano (BOGO, 2011, p. 182-183).

\section{Considerações finais}

Segundo Mészáros (2005), as mudanças devem ir à essência do modo de produçáo capitalista, na qual é necessário perseguir, de modo planejado e consistente, uma estratégia de rompimento com a lógica incorrigível do capital. Para tanto, a transformação progressiva da consciência adquire papel fundamental, tarefa na qual a educação atuaria de maneira central. A educação por si só não modifica a realidade, mas pode alterar a compreensão que os sujeitos sociais possuem a respeito dela, tornando-se, assim, elemento fundamental para o processo de transformação da realidade. Como afirma Sánchez Vázquez (2007):

A teoria em si [...] não transforma o mundo. Pode contribuir para a sua transformaçáo, mas para isso tem que sair de si mesma, e, em primeiro lugar, tem de ser assimilada pelos que hão de suscitar, com seus atos reais, efetivos, tal transformação. Entre a teoria e a atividade prática transformadora se insere um trabalho de educação das consciências, de organização dos meios materiais e planos concretos de ação; tudo isso como passagem indispensável para desenvolver açóes reais efetivas (SÂNCHEZ VÁZQUEZ, 2007, p. 235-236).

Assim, junto à atividade prática transformadora, inserem-se como momentos fundamentais tanto a "educação das consciências" quanto o momento da teoria. Sem teoria não há revolução — como defendia Lênin —, uma vez que: "É a compreensão das determinaçôes mais profundas, é a compreensão da totalidade que permite aos trabalhadores ver a si mesmos como a classe histórica que são, compreender a natureza da forma capitalista e pensar a sua superação" (IASI, 2011, p. 128). 


\section{Notas}

1. No Brasil, a formação política contra a ordem ocorreu de forma mais sistemática a partir dos movimentos de educaçáo popular das décadas de 1950 e 1960, que tiveram como principal referência teórica o educador Paulo Freire. Ascendeu na década de 1960 uma vertente da igreja católica preocupada em transformar as condiçóes de vida dos explorados do sistema, expressa na teologia da libertação, com forte penetração nas manifestações contra a ditadura. A igreja foi uma das únicas organizaçôes que conseguiu persistir no trabalho de formação política durante a ditadura, num momento em que a esquerda ganhava espaço nessa instituiçáo. As comunidades eclesiais de base se fortaleceram nesse contexto.

2. Na década de 2000, mais de 24 mil escolas do campo foram fechadas. Por essa razão, o MST desenvolveu, no ano de 2011, a campanha com o título: "Fechar escola é crime" (MST, 2011).

3. É possível encontrar a programaçáo detalhada, bem como os eixos temáticos e os coordenadores de grupo de trabalho do V EBEM no site: http://www.5ebem.ufsc.br/localgts.php. A liderança do MST e intelectual Ademar Bogo esteve no V EBEM, coordenando uma mesa de apresentação de trabalhos, cujo eixo temático foi "Marxismo, educação e movimentos sociais".

\section{Referências}

BOGO, A. Liçóes da luta pela terra. Salvador: Memorial das Letras, 1999. . Identidade e luta de classes. São Paulo: Expressão Popular, 2008. . Organização política e política de quadros. São Paulo: Expressão Popular, 2011.

CALDART, R. Pedagogia do Movimento Sem Terra. São Paulo: Expressão Popular, 2004. FERNANDES, F. A Universidade brasileira: reforma ou revolução? São Paulo: Alfa Ômega, 1975. . Sociedade de classes e subdesenvolvimento. 5. ed. São Paulo: Global, 2008.

. A revolução burguesa no Brasil: ensaio de interpretação sociológica. 5. ed. São Paulo: Globo, 2006.

FRIGOTTO, G. A década perdida da educação brasileira. In: BENJAMIN, C.; ELIAS, L.A. (Orgs.). Brasil: crise e destino - entrevistas com pensadores contemporâneos. São Paulo: Expressão Popular, 2000.

IANNI, O. Origens Agrárias do Estado Brasileiro. São Paulo: Brasiliense, 1984.

IASI, M. Educação, consciência de classe e estratégia revolucionária. Universidade e Sociedade, Distrito Federal, v. 21, n. 48, p. 122-130, 2011.

LEHER, R. Educação popular como estratégia política. In: JEZINE, E.; ALMEIDA, M.L.P. (Orgs.). Educação e Movimentos Sociais: novos olhares. 2. ed. Campinas: Alínea, 2010.

LENIN, V.I. Obras completas. Moscú: Progreso, 1981. t. 2. 
. O imperialismo, fase superior do capitalismo. In: Obras escolhidas. São Paulo: Alfa Omega, 1986. v. 1.

MANACORDA, M.A. Marx e a pedagogia moderna. Campinas: Alínea, 2007.

MÉSZÁROS, I. A educação para além do capital. São Paulo: Boitempo, 2005.

. O desafio e o fardo do tempo histórico: o socialismo no século XXI. São Paulo: Boitempo, 2007.

MOVIMENTO DOS TRABALHADORES RURAIS SEM TERRA (MST). Fechar escola é crime! Disponível em: <http://www.mst.org.br/2011/05/31/fechar-escola-e-crime. $\underline{\mathrm{html}}>$. Acesso em: 08 set. 2011.

PRADO JR.; C. A questão agrária no Brasil. São Paulo: Brasiliense, 1979.

.Formação do Brasil Contemporâneo. São Paulo: Brasiliense; Publifolha, 2000.

RODRIGUES, F.C. MST - Formação Política e Reforma Agrária nos anos de 1980. 2013. Tese (doutorado). Faculdade de Educação. Universidade Estadual de Campinas. Campinas.

SAMPAIO JUNIOR, P.A. Por que voltar a Lênin? Imperialismo, barbárie e revolução. In: LENIN, V.I. O imperialismo, etapa superior do capitalismo. Campinas: FE/UNICAMP, 2011.

SÁNCHEZ VÁZQUEZ, A. Filosofia da práxis. São Paulo: Expressão Popular: 2007.

SAVIANI, D. Pedagogia histórico-crítica: primeiras aproximaçóes. 10. ed. Campinas: Autores Associados, 2008a.

História das ideias pedagógicas. 2. ed. Campinas: Autores Associados, 2008b.

SILVA, J.G. A reforma agrária brasileira na virada do milênio. 2. ed. Maceió: Edufal, 1997.

TURATTI, M.C.M. Os filhos da lona preta: identidade e cotidiano em acampamentos do MST. São Paulo: Alameda, 2005.

Recebido em 13 de junho de 2016.

Aprovado em 13 de outubro de 2016. 